\title{
EFFICIENT POSITIVE PRESSURE VENTILATION WITH A MODIFIED MAGILL CIRCUIT IN ADULTS
}

(A preliminary study)

\author{
EdWard Carden, M.A., M.B., B.CHIR., F.R.C.P.(c) ${ }^{*}$
}

SOME FORTY-Two YEARS Ago Sir Ivan Magill improvised the Magill circuit which consisted of a reservoir bag, a length of corrugated tubing and a relief valve adjacent to the patient (Figure 1). This was his solution to the problem of connecting a tracheal tube to a gas source. ${ }^{1}$ Later this became known as the Mapleson A circuit following an examination of the theoretical behaviour of various semi-closed anaesthetic systems. ${ }^{2}$ It has been popular in Great Britain and other parts of the world for supplying gases during anaesthesia in spontaneously breathing patients. Experimental studies have shown that under these circumstances, fresh gas flows approximating to the alveolar minute volume can be fed into the circuit without danger of carbon dioxide build-up. ${ }^{3,4}$ However, it was considered that the Magill circuit was unsatisfactory during positive pressure ventilation and consequently it has been argued that its use should be confined to situations in which adequate spontaneous respiration will be maintained throughout the operation. ${ }^{5}$

More recently normocarbia has been shown to be possible with this circuit with controlled ventilation, provided that a fresh gas flow of at least 5 liters is used, together with an increased minute volume, and tidal volumes of one liter or more ${ }^{6,7}$ A modification of the Magill circuit designed for paediatric use has recently been published ${ }^{8}$ which permits positive pressure ventilation resulting frequently even in hypocarbia with the expiratory valve of the circuit closed during the inspiratory phase of positive pressure ventilation, and a fresh gas flow equal to the predicted minute volume, uncorrected for tracheal intubation.

Unfortunately, even though that paper provided a practical approach to the use of this circuit in paediatric anaesthesia, gas leaks from around the uncuffed tracheal tube made it difficult to obtain accurate measurements of the efficiency of the circuit. The object of this paper is to demonstrate the effects of this type of circuit with positive pressure ventilation in adults where cuffed tracheal tubes are used.

Spontaneous ventilation with the Magill circuit is efficient because the dead space gas is rebreathed with each successive breath (Figure 2A), whereas rebreathing results when it is used for positive pressure ventilation (Figure 2B). If the relief valve can be closed during inflation with compression of the reservoir bag and opened at the end of exhalation, then theoretically the system should

-Assistant Professor of Anesthesiology, Department of Anesthesiology, University of North Carolina, School of Medicine, Chapel Hill, North Carolina 27514, U.S.A. 


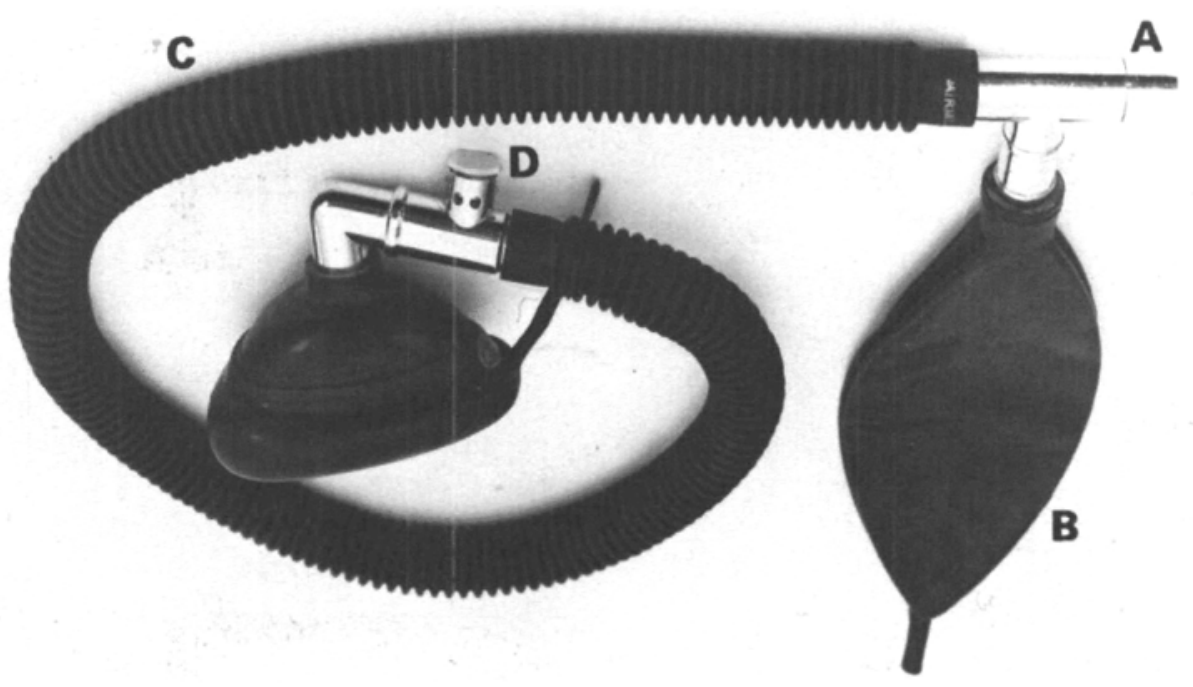

Ficure 1. The Magill circuit. Comprising: (A) T-piece bag mount, (B) reservoir bag, (C) corrugated tubing, (D) relief (Heidbrink) valve.

function as with spontaneous ventilation (Figure 3). It is this matter that we intend to investigate here.

\section{Apparatus}

In order to be able to close the relief valve during inspiration the Magill circuit was modified in the following way (Figure 4):

The relief valve and mount have been replaced by a $\mathrm{Y}$ piece, one limb being connected to the patient, one to the circuit, and the third to a second piece of corrugated tubing on the end of which is a piece of flattened Penrose drainage tube. This tubing acts as a low resistance relief valve which does not open during expiration until the reservoir bag has refilled. It hangs alongside the reservoir bag so that, when the bag is squeezed the drain is compressed at the same time and inflation of the lungs will occur. Upon release of pressure, the bag fills first and thereafter the excess gas will flow out through the new relief valve.

\section{METHOD}

Three studies were carried out.

\section{Study $I$}

Fifteen patients between the ages of thirteen and fifty-two were selected at random for this study. All were undergoing major operations, some being abdominal. All were anaesthetized with a narcotic-relaxant technique and the trachea was intubated with a cuffed tube. The lungs were ventilated by hand with a mixture of nitrous oxide and oxygen $25-40$ per cent, in the manner described, utilizing the special modified Magill circuit shown in Figure 4. Arterial blood samples were taken into heparinized syringes by radial artery puncture 
A.
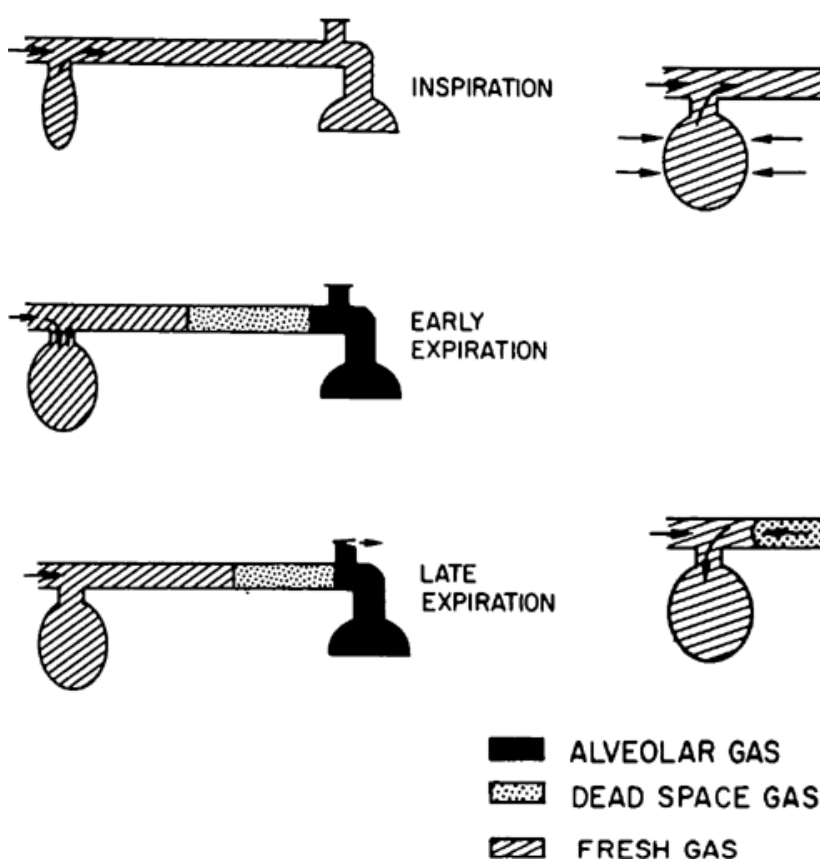

FRESH GAS
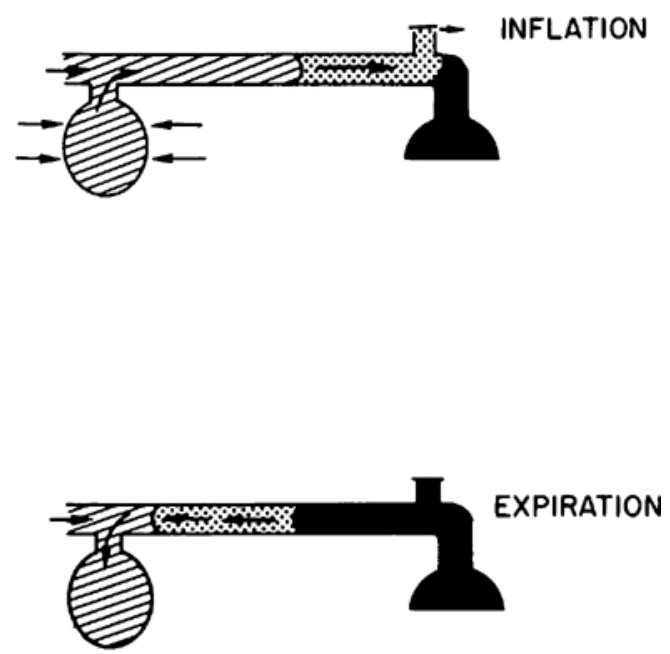

Figure 2. The sequence of events during a single respiratory cycle with a Magill circuit. A. Spontaneous respiration. In the top picture the circuit is seen full of fresh gas and the reservoir bag nearly empty. The dead space gas followed by alveolar gas passes into the tubing until the reservoir bag is full and the relief valve opens. During the later part of expiration further exhaled alveolar gas passes out of the relief valve. Maximum economy is attained when all the alveolar gas is vented but the dead space gas is retained. B. Positive pressure ventilation: The top picture shows inflation. The relief valve is tightened up so that some gas leaks from it and some goes to the patient. During expiration (seen in the lower picture) the circuit fills with dead space and alveolar gas and no gas leaks from the relief valve.

and were analyzed immediately on an IL Model 113 blood gas analyzer. The minute volumes were calculated from the Radford Nomogram ${ }^{9}$ but no corrections were made for intubation, since the dead space is rebreathed with this circuit, the size of dead space should not affect carbon dioxide removal and the uncorrected volume was therefore used as a base line. A fresh gas flow equal to this volume was used for 15 minutes and an arterial blood sample was then taken and analyzed. Thereafter the fresh gas flow was reduced to 75 per cent of the original and the lungs were ventilated for another 15 minutes, a second arterial blood sample was then taken and analyzed. Ventilation was increased if this second sample showed a $\mathrm{PaCO}_{2}$ of more than 40 torr, and in that case a third blood sample was taken 15 minutes later. It follows that in some patients two blood samples were needed, and in some three.

\section{Study II}

In order to compare the efficiency of this circuit with a non-rebreathing circuit and with the standard Magill circuit the following experiment was undertaken. 


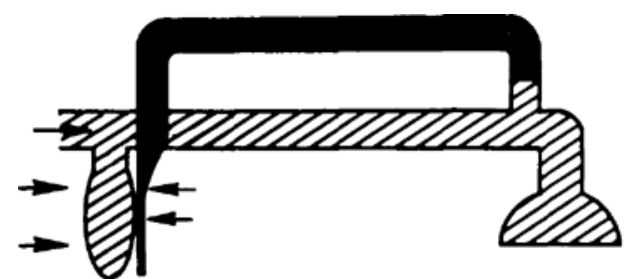

INSPIRATION

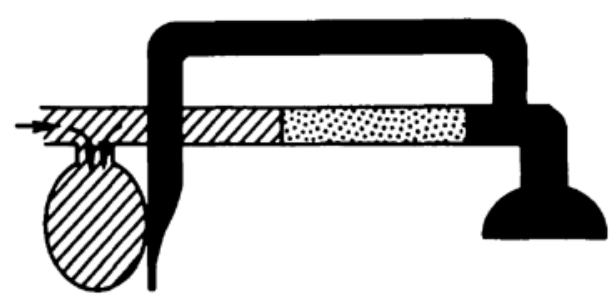

\section{EARLY}

EXPIRATION

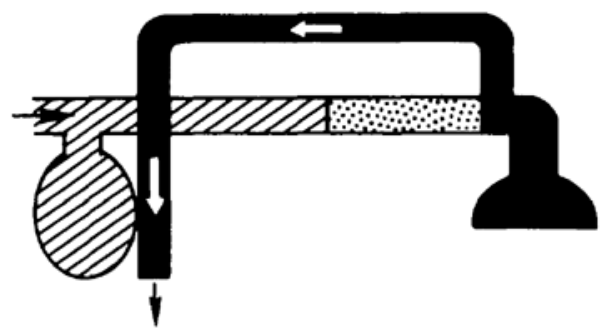

LATE

EXPIRATION

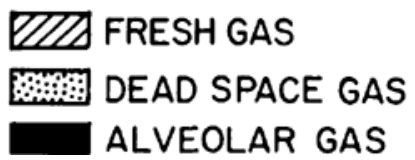

Figure 3. The sequence of events during a single respiratory cycle of positive pressure ventilation with the special Magill circuit. The top picture shows inflation. The relief valve is closed so that no gas leaks from it and all the gas goes to the patient. During expiration (middle and lower pictures) the circuit fills with dead space and fresh gas. The alveolar gas leaks from the relief valve. The same sequence will occur during spontaneous respiration.

The lungs of a patient undergoing hysterectomy were ventilated with a Magill circuit incorporating a non-rebreathing valve (Ambu) as replacement for the relief valve. Ventilation was at a rate of ten per minute with a fresh gas flow equal to the uncorrected predicted minute volume. An arterial blood sample was drawn and analyzed after twenty minutes. The non-rebreathing valve was then replaced with the normal relief valve and ventilation continued with a tidal volume of 1000 cc (measured on a Wright's Respirometer). After 20 minutes a further arterial blood sample was taken and analyzed. The modified Magill circuit was then connected and the lungs were ventilated at the same rate and with the same tidal volume 
CANADIAN ANAESTHETISTS' SOCIETY JOURNAL

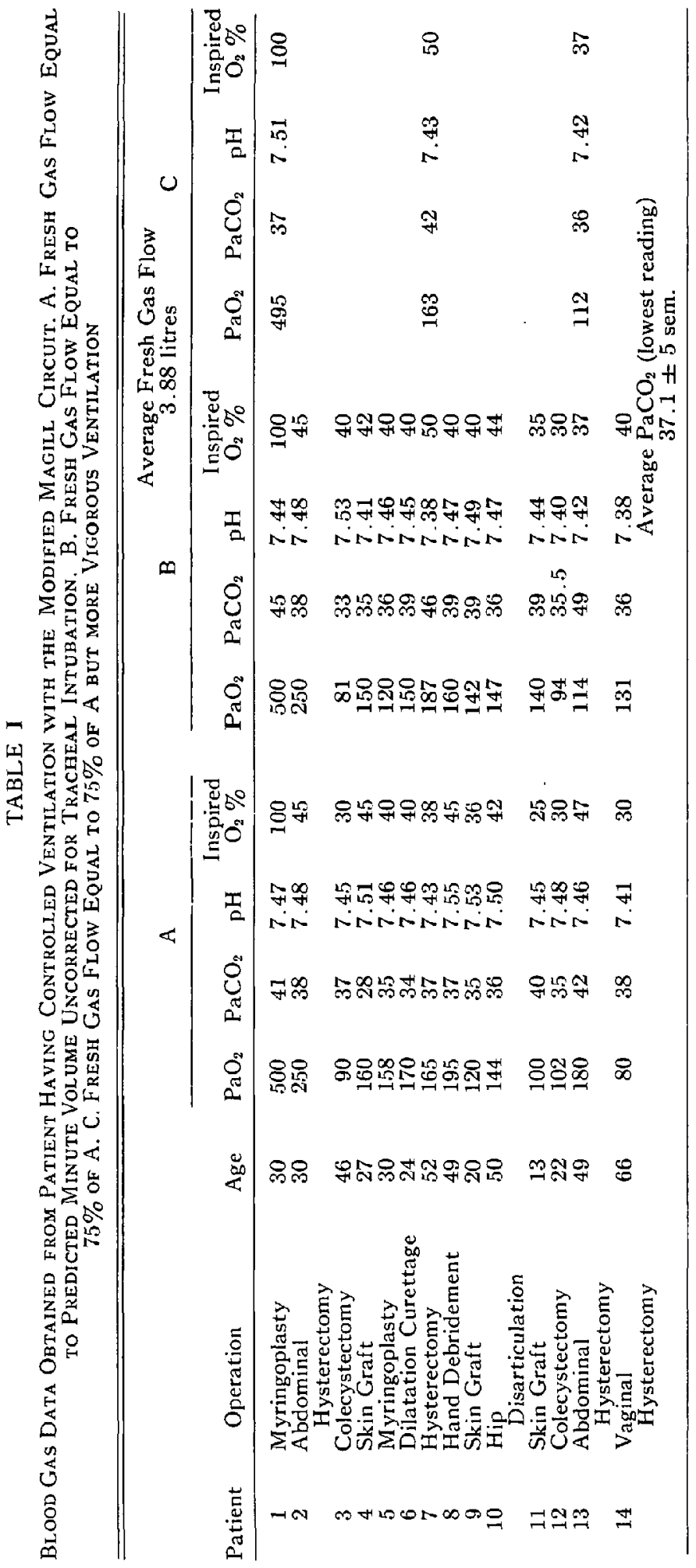



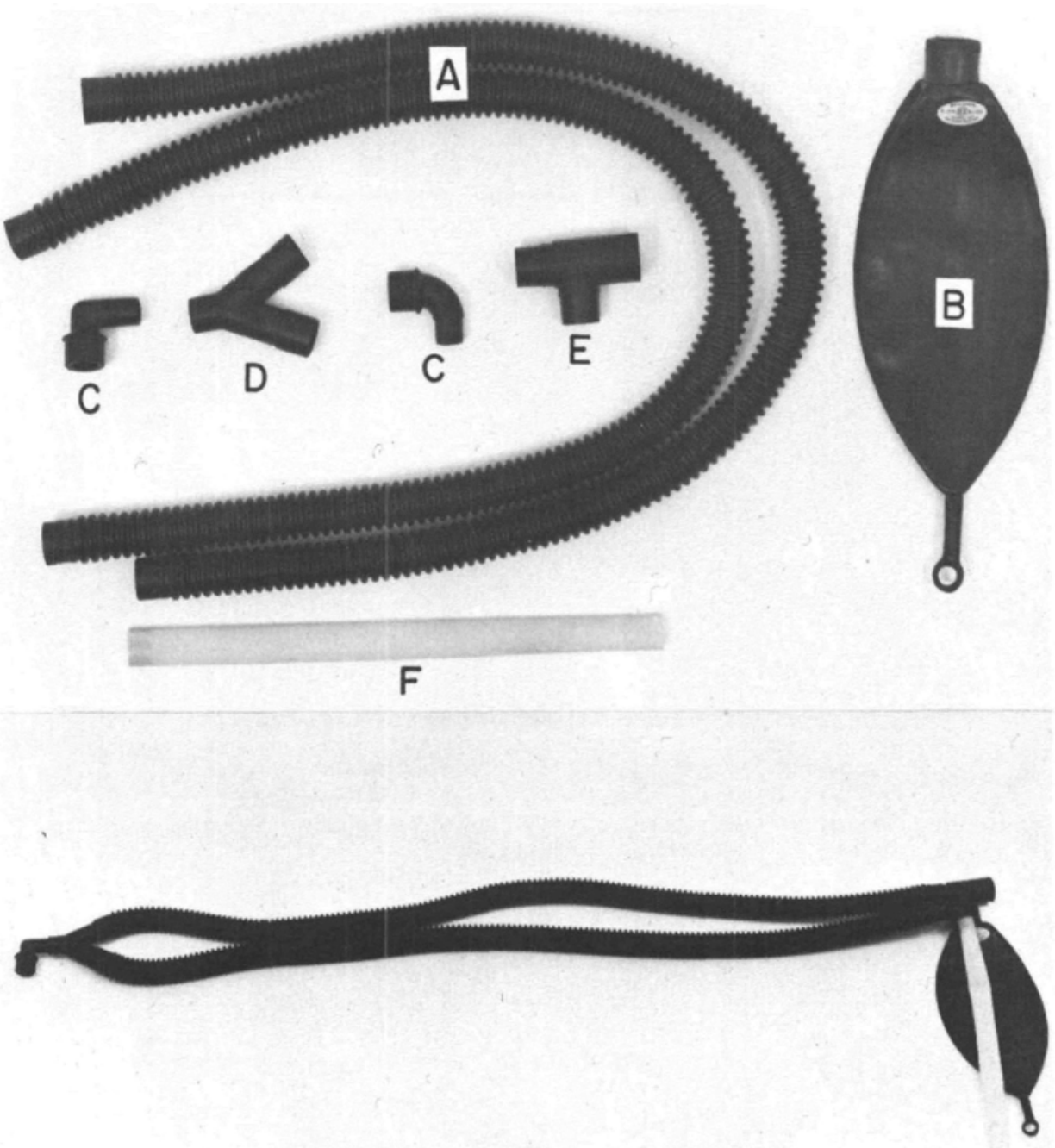

Figune 4. Above: The parts needed for this circuit: (A) 2 lengths of corrugated tubing, (B) reservoir bag, (C) $90^{\circ}$ connector, (D) Y piece, (E) bag mount, (F) Penrose drain tubing. Below: The circuit assembled.

again for 20 minutes when a further arterial sample was taken and analyzed. The procedure was then repeated in the reverse order. The results are seen in Table II.

\section{Study III}

Finally, since increased ventilation was required in three patients in the first experiment it was essential to find out if hyperventilation was needed to ensure efficiency in the circuit. Consequently the lungs of one patient were ventilated with 6 to 14 litres per minute as measured with a Wright's respirometer interposed between the circuit and the tracheal tube. A fresh gas flow of 75 per cent of the uncorrected predicted minute volume was administered and arterial samples taken after ten minutes at each different minute volume. The results are 


\section{TABLE $\|$}

\begin{tabular}{|c|c|c|c|c|c|}
\hline \multicolumn{6}{|c|}{$\begin{array}{l}\text { Patient's Age, } 35 ; \text { Operation, Hysterectomy; Predicted } \\
\text { Minute Volume, } 4.5 \text { Litres; Fresh Gas Flow, } 4.5 \text { Litres }\end{array}$} \\
\hline Circuit & $\begin{array}{l}\mathrm{PaO}_{2} \\
\text { Torr }\end{array}$ & $\underset{\text { Torr }}{\mathrm{PaCO}_{2}}$ & $\mathrm{pH}$ & $\begin{array}{l}\text { Rate/ } \\
\text { Min }\end{array}$ & $\begin{array}{l}\text { Tidal Vol. } \\
\quad \text { CCS }\end{array}$ \\
\hline \multicolumn{6}{|l|}{ Non- } \\
\hline Rebreathing & 250 & 37 & 7.4 & 10 & 450 \\
\hline $\begin{array}{l}\text { Magill } \\
\text { Modified }\end{array}$ & 230 & 40 & 7.4 & 10 & 1000 \\
\hline $\begin{array}{l}\text { Magill } \\
\text { Modified }\end{array}$ & 240 & 33 & 7.41 & 10 & 1000 \\
\hline Magill & 220 & 33 & 7.39 & 10 & 1000 \\
\hline Magill & 210 & 43 & 7.31 & 10 & 1000 \\
\hline $\begin{array}{l}\text { Non- } \\
\text { Rebreathing }\end{array}$ & 235 & 38 & 7.35 & 10 & 450 \\
\hline
\end{tabular}

TABLE III

Showing Arterial Blood Gas Results Obtained While, Ventilating the Lungs with Different Minute Volumes Utilizing the Modified Magili Circuit and the Same FrESH GAS FLOW

\begin{tabular}{ccccc}
\hline \hline \multicolumn{5}{c}{$\begin{array}{c}\text { Patient's Age, 35; Operation, Ventral Hernia Repair, } \\
\text { Anesthesia } \\
\text { Balanced; Predicted Minute Volume, } \\
\text { Fresh Gas Flow, } \\
\text { F.35 Litres }\end{array}$ (75\%) } \\
\hline $\begin{array}{c}\text { Min. Vol. } \\
\text { CCS }\end{array}$ & Tidal Vol. & $\mathrm{PaO}_{2}$ & $\mathrm{PaCO}_{2}$ & \\
\hline 6000 & CCS & Torr & Torr & $\mathrm{pH}$ \\
10000 & 600 & 240 & 40 & 7.4 \\
14000 & 1000 & 245 & 41 & 7.405 \\
12100 & 1200 & 245 & 40 & 7.41 \\
10100 & 600 & 250 & 41 & 7.41 \\
6750 & 600 & 250 & 41 & 7.39 \\
5700 & 500 & 250 & 42 & 7.37 \\
\hline
\end{tabular}

seen in Table III. Ventilation was carried out by anaesthesiologists, nurse anaesthetists, and anaesthesia residents. Patients were monitored for EKG changes, blood pressure changes, and pulse rate changes. No changes other than those normally encountered were observed while this circuit was in use.

\section{Discussion}

The theoretical analysis of this circuit shown in Figure 3 predicts that the dead space in the circuit is rebreathed with each successive breath and, therefore, a fresh gas flow of less than the predicted minute volume should provide normocarbia. Results (Table II) amply demonstrate that this circuit is more efficient than a non-rebreathing circuit with the same fresh gas flow. This efficiency of ventilation is quite consistent as can be seen from the arterial carbon dioxide values shown in Figure 1. What is interesting, however, is that large changes in patient minute volume have little or no effect on arterial carbon 
dioxide tension (Table III). The theoretical analysis in Figure 3 does not show the effects of ventilation with minute volumes larger than normal but the same fresh gas flow. When this happens rebreathing of alveolar gas will of necessity occur. As the minute volume increases the concentration of carbon dioxide in the inhaled gas also increases, and the two compensate for one another, thereby keeping the carbon dioxide tension unchanged. Another way to look at this is to realize that only end-tidal gas equilibrated with arterial blood escapes into the expiratory limb. Consequently it should only need approximately 3.8 litres of fresh gas to equilibrate with the $200 \mathrm{cc}$ of carbon dioxide being produced by the average patient to produce a total of 4 litres of 5 per cent carbon dioxide. In these calculations a carbon dioxide averaging 37.1 torr is obtained with fresh gas flows averaging 3.8 litres. One should be able to predict that carbon dioxide build-up should occur if the minute volume falls below normal, and, in fact, in Table III, one can see this beginning to happen.

When a new circuit is tested it is important to know if it will have practical application. It seems that there should be a practical application of this circuit even if it does not retain the same physical shape. Ventilation can be easily performed and can be expected to provide a consistent arterial carbon dioxide level which will be dependent upon the fresh gas flow and independent of the ventilation, provided that a fresh gas flow in excess of minute volume is being delivered. Fresh gas flow in the order of 4 litres per minute can be expected to result in arterial carbon dioxide levels in the region of 40 torr in the average patient. This gas flow is less than that commonly used by most anaesthetists who are using soda lime in a circle system. The exhaust of this system could quite easily be led to a vacuum system to eliminate anaesthetic gases from the operating room. Since no soda-lime is needed the cost of this system should be relatively small. An added advantage is that inexpensive trichloroethylene may be used with it.

Non-rebreathing circuits suffer from the problem of the breathing of dry gases. Since in our circuit patients are rebreathing at least the dead space volume, a fair amount of humidity is present in the inspired gas and, in fact, the more the hyperventilation the higher the humidity. The circuit will function as a normal Magill circuit during spontaneous respiration, so maintaining its efficiency for both types of ventilation.

These preliminary studies indicate that this circuit may have a definite potential in the future. A more elaborate variety of this circuit, together with a more sophisticated analysis of its function, is being prepared.

\section{ConcLusion}

By modifying a Magill circuit so that the relief valve can be closed during inflation and can open during exhalation after the reservoir bag has refilled, the circuit can be used efficiently with controlled ventilation. Preliminary studies indicate predictable physiological arterial carbon dioxide levels with fresh gas flows below those normally needed with a non-rebreathing circuit. 


\section{RÉSUMÉ}

Nous avons modifié un circuit de Magill de façon simple, afin de permettre une ventilation avec fermeture de la valve expiratoire durant l'application de pression positive et ouverture de cette valve après le remplissage du sac réservoir.

Des opérés furent ventilés manuellement avec ce système et avec un débit de gaz frais de 75 pour cent du volume minute prédit (volume non corrigé pour l'intubation). Les $\mathrm{PCO}_{2}$ se sont maintenues entre 36 et 42 torr. A l'usage ce système s'est avéré supérieur à la ventilation avec un circuit sans réinspiration, lequel est lui même supérieur à un circuit de Magill non modifié. Avec un apport constant de gaz frais, le circuit modifié maintenait des niveaux de $\mathrm{CO}_{2}$ constants, même en présence d'hyperventilation vigoureuse.

\section{ACKNOWLEDGMENTS}

The author wishes to thank Dr. W.W. Mapleson, Ph.D., for his invaluable, constructive criticism, and Mrs. Tance Smith for her secretarial help.

\section{REFERENCES}

1. MagiLl, I. Endotracheal anesthesia. Proceedings of the Royal Society of Medicine 22: 83 (1928).

2. MAPLESon, W.W. Elimination of rebreathing in yarious semi-closed anaesthetic systems. British Journal of Anaesthesia 26: 323 (1954).

3. Kain, M.L. \& NunN, J.F. Fresh gas economics of the Magill circuit. Anesthesiology 29: 964 (1968).

4. Norman, J., Adams, A.P., \& Sykes, M.K. Rebreathing with the Magill attachment. Anaesthesia 23: 76 (1968).

5. SYKES, M.K. Rebreathing during controlled respiration with the Magill attachment. British Journal of Anaesthesia 31: 247 (1959).

6. Waters, D.J. \& MAPLESON, W.W. Rebreathing during respiration with various semiclosed anaesthetic systems. British Joumal of Anaesthesia 33: 374 (1961).

7. Marshall, M. \& Henderson, G.A. Positive pressure ventilation using a semiclosed system: a reassessment. British Journal of Anaesthesia 40:265 (1968).

8. CaRdEN, E. A new and highly efficient circuit for pediatric anaesthesia. Canadian Anaesthetists' Society Journal 19:572 (1972).

9. RADFORD, E.P. Ventilation standards for use in artificial respiration. Journal of Applied Physiology 7: 451 ( 1955). 